\title{
Erratum to: A new strategy for MS/MS data acquisition applying multiple data dependent experiments on Orbitrap mass spectrometers in non-targeted metabolomic applications
}

\author{
Graham Mullard • J. William Allwood • Ralf J. M. Weber • Marie Brown • \\ Paul Begley • Katherine A. Hollywood • Martin Jones • Richard D. Unwin • \\ Paul N. Bishop · Garth J. S. Cooper · Warwick B. Dunn
}

Published online: 14 January 2015

(C) Springer Science+Business Media New York 2015

\section{Erratum to: Metabolomics}

DOI 10.1007/s11306-014-0763-6

In the original version of this paper, the second and thirdlisted authors are named James W. Allwood and Ralf Weber. Their names should appear as J. William Allwood and Ralf J. M. Weber.

The online version of the original article can be found under doi:10. 1007/s11306-014-0763-6.

G. Mullard · M. Brown · P. Begley · K. A. Hollywood . R. D. Unwin · P. N. Bishop - G. J. S. Cooper - W. B. Dunn Centre for Endocrinology and Diabetes, Institute of Human Development, Faculty of Medical and Human Sciences, The University of Manchester, Manchester M13 9WL, UK

G. Mullard · M. Brown · P. Begley · K. A. Hollywood · R. D. Unwin · P. N. Bishop - G. J. S. Cooper · W. B. Dunn Centre for Advanced Discovery and Experimental Therapeutics (CADET), Central Manchester University Hospitals NHS Foundation Trust, Manchester Academic Health Sciences Centre, Manchester M13 9WL, UK

J. William Allwood · R. J. M. Weber · M. Jones ·

W. B. Dunn $(\bowtie)$

School of Biosciences, University of Birmingham, Edgbaston, Birmingham B15 2TT, UK

e-mail:w.dunn@bham.ac.uk

\section{P. N. Bishop}

Centre for Hearing and Vision Research, Institute of Human Development, Faculty of Medical and Human Sciences, The University of Manchester, Manchester M13 9WL, UK

\section{G. J. S. Cooper}

Maurice Wilkins Centre for Molecular Biodiscovery, Faculty of Science, University of Auckland, Auckland 1020, New Zealand

\section{G. J. S. Cooper}

Department of Pharmacology, University of Oxford, Mansfield Road, Oxford OX1 3QT, UK 